\title{
What Happened to the Public Spaces of the Arab World? From Colonisation to Revolution: The Case of Lebanon
}

\author{
Tarek Fouani \\ tarekfouani3@gmail.com
}

\begin{abstract}
This paper critically assesses the circumstances under which the European idea of public spaces was imported and implemented in the Arab context. Starting with an overlook of the periods and the initial intentions behind the implementation of these spaces and going deeply into the case study of Lebanon. The context of Beirut, Lebanon acts as the set example of the whole paper with a look at the influence of colonisation and the unsettling situation post-independence, which resulted in an unbalanced development of the city with the various influencing factors that were deducted as mainly political and economic rather than social or cultural. With that background, the paper deduces that the intense political and colonial influences that led to the replication of the European public spaces in the Arab context were not sufficient for their success. This is backed up through a comparative study between Martyr's Square in Beirut and Piazza di Duomo in Milan, which share a similar form, but different culture and process of implementation. By reaching this conclusion, the importance of the social and cultural aspects in the success of public spaces was emphasized through a close spatial analysis of the example of the Lebanese revolution in October 2019, which was able to transform those spaces. This marked a proof as for how the essence of public spaces and their development should react to the needs of the people and their culture. It looks at how public spaces are made by the people. Nevertheless, the paper acknowledges the disparities between the regimes and systems of different Arab countries.
\end{abstract}

Keywords: political influence, social identity, public space, Beirut, revolution

To cite this article:

Fouani, T. (202I) What Happened to the Public Spaces of the Arab World? From Colonisation to Revolution: The Case of Lebanon, The Journal of Public Space, 6(I), 203-2 I4, DOI I0.3289I/jps.v6il.I308

This article has been double blind peer reviewed and accepted for publication in The Journal of Public Space.

(c) (1) \$ This work is licensed under a Creative Commons Attribution - Non Commercial 4.0 International License https://creativecommons.org/licenses/by-nc/4.0/ 


\section{Introduction}

A public space is meant to be the facilitator of democracy within a community (Rabbat, 2012). It is the space where people from all backgrounds gather and interact in a form of self-expression that enables the acceptance of their differences. This leads to the formation of a collective identity and vision towards the future. With the dominance of Islamic religion in the Middle East and the Arab world, it acted as the basis of the formation of gathering spaces in the region, reflected through the mosques (Rabbat, 2012). The mosque was the main space for gathering, and the operation room for all events, and even protests. Later on, and with the colonisation of several Arab countries by the Ottomans and then by European countries, their western ideologies spread into the Arab world where both tried to integrate the western public space into the Arab world in an intention of modernising its "oriental cities" (Fawaz, 2014). The journey continued even post-independence without the absence of the influence of the excolonial authorities as we will see in the city of Beirut, Lebanon later on. This process faced a lot of obstacles, as it imposed a foreign ideology with a lack of consideration of the disparities between western and Arab countries regarding the cultural, political, environmental, social and religious factors.

This paper will tackle this issue and try to answer whether the circumstances of implementation of the European public spaces in the Arab world were sufficient for their success, and what other factors that are essential to ensure the success of these public spaces. This divides the question into three objectives that the paper will strive to achieve. The first objective will be discussed as part of the literature review to first understand under what circumstances were the public spaces imported to the Arab region, and conclude the factors that influenced this importation. The second objective under the title "Evaluating spaces" is to evaluate the success, or failure, of the European-influenced public spaces in the Arab context. The third and final objective titled "Factors of success" would be to identify the lacking factors that have or could have played a major role in the transformation and domestication of these spaces.

In that manner, the literature review will give an overview on public spaces in Europe and their history, to further discuss the history and process of how these spaces were imported into the Arab world, with a focus on Lebanon and the pure role of politics. Moreover, after defining the methodology, the findings and discussion will go in parallel, and will be divided into two parts, each solely working towards the two objectives respectively. The first part will be achieved through a comparative study of two public space, one in Europe and the other in Lebanon; and the second part will achieve the last objective through a spatial analysis of the influence of the Lebanese revolution in 2019 on the use of the public spaces in Beirut. The focus on these will be on the social and cultural aspects.

\section{Literature Review: Public spaces: from a European to an Arab context}

As ancient Greece had its agora, Arabs had their mosques and medieval Europe had its public squares (Arch2o, 2020); so, what happened to the public spaces in the Arab world after the latter was imposed on it? When speaking of the success of public spaces in European cities, we need to understand that these spaces are born through a continuous historical evolution (Lennard, 2004). The process morphed them within the fabric of their cities, such as those in Italy and Greece. Such cities were built around 
these spaces, guided by proportions and harmony with intended uniformity that holds you once you are there (Lennard, 2004). Also, it was part of the city's formations, as it blended with religious and civic activities, housed temples and basilicas, shops and markets, theatres and public baths, which took part in embracing the space's significance (Arch2o, 2020).

The European idea of a public space, or a square, started in the medieval western cities, and was introduced to the Arab world with an influence of colonial authorities. This began with the Ottoman Empire, which was influenced by the European standards in its developments (Rabbat, 20I2), and then with the mandates of France over Lebanon, Syria, Tunisia and Algeria, Britain over Palestine, Jordan and Iraq, and Italy over Libya. This was a period between the late $19^{\text {th }}$ century until early-to-mid $20^{\text {th }}$ century, where most of these countries gained their independence in 1943.

The implementation was intended by the colonial authorities in order to provide its colonial settlers and military with a familiar European urban environment (Faleh, 2020). An example of this would be Tunisia's Habib Bourguiba Avenue that was designed by the French during colonisation (188I-1956) for the elite as an image of the ChampsÉlysées (Faleh, 2020). It also intended to distinguish between the new development and the traditional city, as illustrated in Figures $I$ and 2.

A variety of foreign ideologies came along, those of which are social, economic, and cultural structures that were translated into alterations in the built environment (Rabbat, 20I2). These alterations resulted in attracting the upper class and wealthy inhabitants, leading to a stronger social division, and also, leading several Arab cities, such as Algiers, Tunis, Cairo, Damascus, Beirut, Baghdad and Aleppo to enter the $20^{\text {th }}$ Century with dualistic urban developments that were hybridized and heterogeneous (Rabbat, 20I2). These two halves were represented as the modern and the traditional. That period came in parallel with the modernist movement, which through its functionalism, gave priority to the vehicular morphology. It undermined the relationship between a space and a building, and gave little attention to the evolution that forges the public realm with its history and identity; which is deemed essential in making it successful (Arch2o, 2020). It is undeniable that this movement had an influence on the erection of public spaces in Arab cities, where the main vision was in "modernising" them.

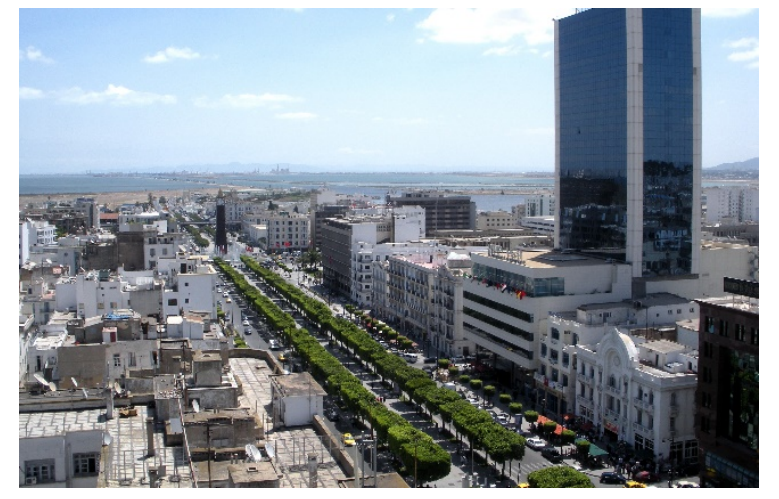

Figure I. Habib Bourguiba Avenue -Tunisia (from: thetravelmagazine.ne)

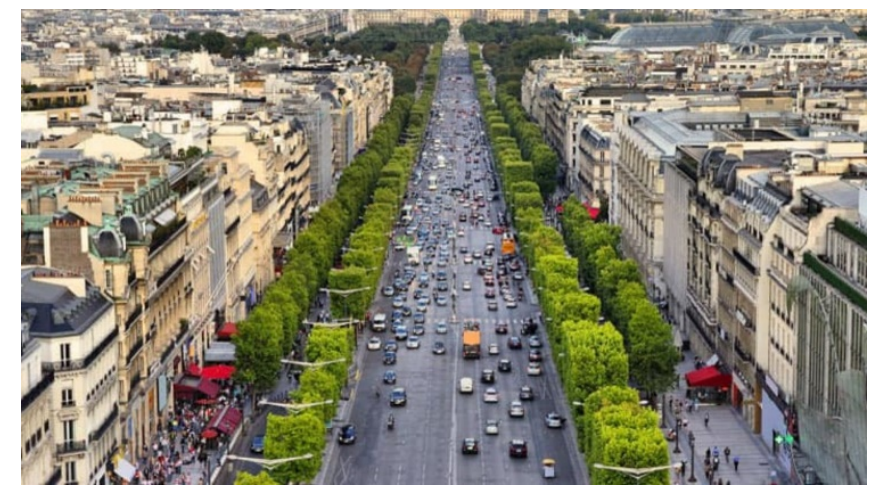

Figure 2. Champs-Élysées -Paris, France (from JVelez) 


\section{The circumstances of Lebanon}

After Lebanon gained its independence in 1943, the marks of the French mandate remained as a main feature in the city. Streets were named after victorious French generals of the World War I, such as Foch, Weygand and Allenby (Verdeil et al., 2008). As the downtown area of Beirut followed the "star shape" planning of Paris, also its public squares were superimposed on the existing old fabric of the city, such as "Place de L'Etoile" which was implemented in the 1930s, as shown in Figure 3.

Post-independence, the colonial influence of the French authorities continued through some construction firms such as APUR (Atelier Parisien D'Urbanisme) and IAURIF (Institut d'aménagement et d'urbanisme de la région lle-de-France), with a plan to modernise the city (Verdeil et al., 2008). However, their process was based on class and economic profit rather than the collective culture and identity of the city (Fawaz, 2014). In parallel, Lebanon faced an unstable period prior to its independence, leading to the outbreak of a civil war that lasted I5 years from 1975 until 1990. Throughout, various peace agreements were achieved, however, the tension, especially on the demarcation lines, which remained, led these agreements to failure. This created an unclear boundary between the time of destruction and that of the reconstruction of the city, where a variety of reconstruction initiatives started and stopped due to the renewal of the engagements. All these attempts left their imprints on the city, leaving it as an outcome of several plans of reconstruction that were never completed (Verdeil et al., 2008). Together, they formed a heterogeneous urban fabric.

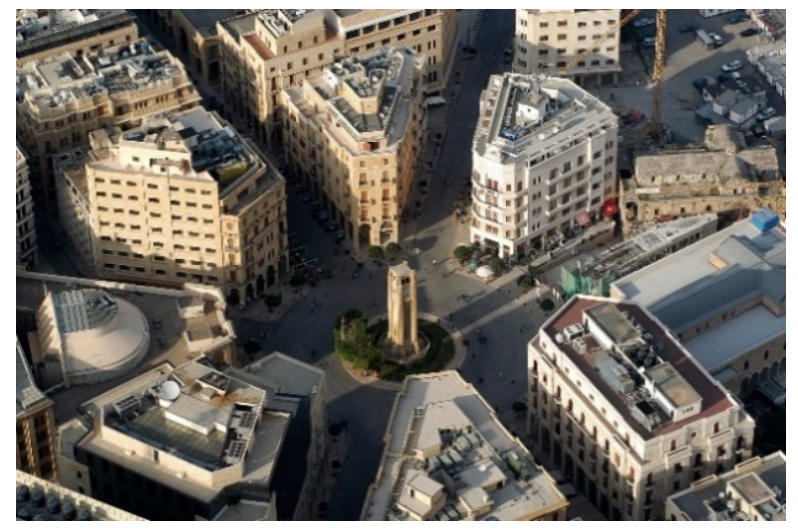

Figure 3. Place de L'Etoile -Beirut, Lebanon (from Annahar)

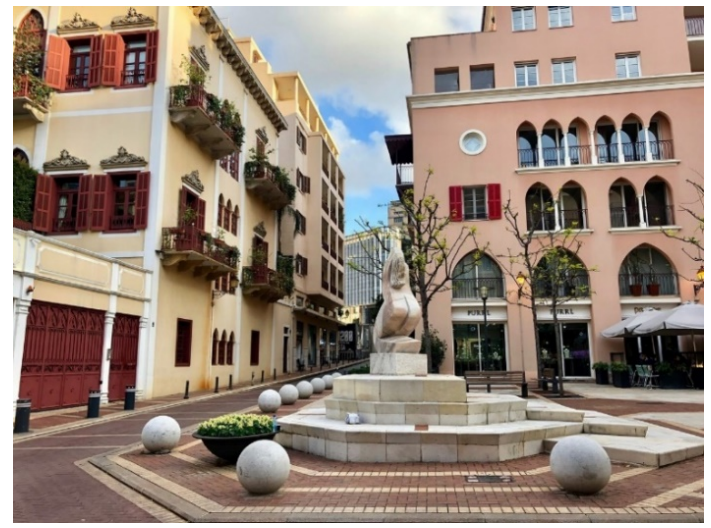

Figure 4. Residential Area of Solidere Reconstructions Post-War (from Tripadvisor Review by Corinne C, 20I2)

After the war, reformations started in Lebanon, and specially in Beirut central district, which suffered drastically from the civil war (Sinno, 2020). In that manner, reconstruction began, but was mostly based on political powers under a sectarian authority, rather than the livelihood of the city and its citizens. The main aim was to foster economy, tourism, trade and real estate, while keeping balance between the conflicting sides (Verdeil et al., 2008). Eventually, reconstruction was commissioned to the Council for Development and Reconstruction; and in 1994, Solidere was formed as a real estate company responsible for the reconstruction of the city centre of Beirut (Sinno, 2020). The privatisation of the city centre made it lose its public essence. Due to 
reasons such as high security, affiliations to certain political parties, the high prices and high real estate costs, the city was deemed accessible only for a minority of the upper class.

Solidere is the French acronym for the Lebanese Company for the Development and Reconstruction of Beirut Central District, incorporated as a Lebanese-joint stock company in 1994 (Van Pinxteren, n.d.). It is a private corporation that was given full control of Beirut's historic centre and adjacent areas by the government. The reconstruction plan of Solidere focused on business, finance, real estate, tourism and leisure (Verdeil et al., 2008). This came at the expense of the heritage and the old landowners and tenants. However, the projects took it further to come at the expense of the centre's identity and history, demolishing wide parts of the city, more than just the war-damaged structures (Verdeil et al., 2008). The benefit was for the private interest, as the state was focused on institutional reforms post the war (Verdeil et al., 2008). These demolitions widely included heritage buildings that were officially protected, and were replaced by towers or "trendy" entertainment spots.

From the literature that was put forward, we can deduct a variety of factors that influenced the circumstances in which public spaces were brought to the Arab world. Some of these factors, as seen in the case of Lebanon, were the influence of the colonial authorities, economic ambitions and profit, wars and the political powers and affiliations. In that manner, we could see that the main players in the implementation of public spaces were political and economic rather than social and cultural; two elements that were highly missing from the literature.

Rebuilding a city in the Arab world, a city torn by war and holding layers of unique social behaviours, cultural traditions, demographic diversity and an identity that was constructed with decades of struggle, became an outcome of politics and profit; of which did not address the actual needs of its citizens. Eventually, the vision for a worldclass project, that can be compared to European standards, resulted in a high-cost area that did not play any role in the social transformation, but rather made it almost impossible to rent, work or live in the city centre (Verdeil et al., 2008). A major difference that we could realize in this process between these public spaces in European cities and in Beirut is their historical evolution within the development. In European cities, as mentioned in the literature, these spaces were forged within the urban fabric and its morphology as they developed through history (Lennard, 2004). They were also well studied and included a variety of functions and activities that gave them significance (Arch2o, 2020). In the case of Beirut, they were imposed on an existing fabric that came in different periods and styles, and some of which was an outcome of a war. Eventually, the identity of these spaces in Beirut and other Arab cities were transformed to become memorials of wars and battles, which was reflected in their new names, such as "Martyr's Square” in Beirut, Lebanon and "Tahrir (Freedom) Square” in Cairo, Egypt.

\section{Methodology}

The critical analysis of the literature review deduced that the circumstances that introduced the European public spaces into the Arab world and specifically Beirut, Lebanon were purely political and economic. This resulted in spaces that replicated European standard, but did not take into consideration the social and cultural needs of the city and its people. This satisfies the first objective of the paper that tries to 
understand the factors and circumstances that influenced the implementation of public spaces in the Arab context, with the case study of Lebanon. Following this idea, the methodology will draw the way to shed the light on the aftermath of such a process, assessing it, and then taking a look at the social and cultural factors that were completely missing, and identifying their inevitable importance in designing public spaces. This will be studied through a methodology that will be divided into two parts, each dealing with the second and third objectives stated in the introduction respectively. The approach towards satisfying these objectives will serve the sole purpose of the paper into answering the research question and deducing the influential factors for successful design of public spaces.

Firstly, in order to achieve our second objective (Evaluating spaces) of evaluating and assessing the success, or failure, of the European-influenced public spaces in the Arab context, specifically in Beirut, Lebanon, a comparative analysis will be done. This comparison will be between two public spaces, one in Europe and other in Beirut, in which they are aesthetically similar. The approach of having them physically similar allows us, to a certain extent, to remove the aesthetic variable of their success or failure from our comparison. For that purpose, the chosen public spaces are Martyr's Square in the city centre of Beirut, Lebanon and Piazza del Duomo in Milan, Italy. This study will be based on statistics gained from readings and a personal observation of both spaces, including their use, surrounding functions, and activity within them through the day and night.

Thereafter, in order to satisfy and achieve the third objective (Factors of success) of identifying the factors that have a major role in transforming and domesticating those spaces, we will follow a live example that took place in Beirut, Lebanon in October, 2019. In that date, a very clear transformation took place of the public spaces in Beirut. This event was the Lebanese revolution that reclaimed these public spaces. In order to deduct the factors that played a role in this transformation and its impact on the use of such spaces, a close look and analysis of how this process was made will take place. In that matter, the methodology will analyze three public spaces that witnessed such transformation; with a focus on its social and cultural aspect. These spaces being "The Egg”, Samir Kassir Garden and Martyr's Square; all located in the city center of Beirut. The analysis will be done through a first-hand spatial analysis of these "public spaces" before and after the Lebanese revolution.

\section{Evaluating spaces}

According to UN-Habitat, public spaces in the Arab world covers around $2 \%$ of the total area, compared to $12 \%$, on average, in European cities (The Economist, 2016). In Beirut, it makes up around only $0.5 \%$ (The Economist, 2016). A main reason for these contrasting percentages is the high density of Beirut that was due to a huge flow of immigration, either from surrounding countries, or internal migrations to the capital. This resulted in a density of 36, 185 inhabitants per square kilometres in Beirut (Metrics, 2020) compared to 2,029 inhabitants per square kilometres in Milan, Italy, for example (Comero et al., 20I5). Milan also has an area coverage of $12.9 \%$ of public spaces (Comero et al., 20I5).

Martyrs' Square is a huge square in the city centre of Beirut, with a significant landmark in its centre, symbolising the long history of struggle towards independence, called The 
Martyrs' Statue. However, this space is now turned into a parking lot, where one can rarely, if ever, see anyone walking or sitting.

To interpret this condition of Martyr's Square, we will compare it to another square that is similar in its form and aesthetics, which will allow us to solely focus on the variables of those influenced by functional, social and cultural factors. The square in study will be Piazza del Duomo in Milan, Italy. Both squares experienced a historical evolution growing from the city.

The development

However, as Martyrs' Square dates back to the $18^{\text {th }}$ century, Piazza del Duomo was first created in the $14^{\text {th }}$ century (Niko, 2016). Aesthetically, they both follow a rectangular shape of an approximate similar area, marked by a statue in the middle, and located in the city centre. In Piazza del Duomo, the statue of the first king of Italy, Victor Emanuel II, marks a significant historical monument (Klaos, 2018), like Martyr's Statue in Beirut. Looking towards the history of construction of the squares,_Martyrs' Square faced a series of battles and wars; later, a 2005 plan of re-designing the public square took place. However, the outcome still failed to revive it (Verdeil et al., 2008). Privatisation also had a major impact on the formation of those spaces. Although part of Piazza del Duomo was privatised due to financial problems, the government was able to set obligation for it to be completed based on the existing plan (Camero et al., 2016). Unlike in Beirut, where the whole area was completely privatised and commissioned to Solidere, with the absence of any governance. This absence was due to the focus of the government on institutional reforms post-war (Verdeil et al., 2008). The outcome of this privatisation could be reflected in the focus on profitability through the upper-class restaurants and shops surrounding it, rather than a focus on the inclusivity and identity of the square itself. This created a space without a clear distinction between what is public and what is private. Such "non-places" lose their symbolic meaning and expression and lack any identity (Arch2o, 2020); to remain only as spaces for the upperclass consumption.

The morphology

Looking at both images below (Figures 5 \& 6), we can notice the physical resemblance, however, we can also realize at the first glance the main issue today. Morphologically, in mid- $19^{\text {th }}$ century, Martyrs' Square was considered a hub for public transportation with its strategic location that connects Beirut to its northern side, and with the tramway station located just around its corner. At that time, this was a factor that helped in reviving the square. Besides the coffee shops, restaurants and other shops nourishing its ground floor at the time. Nowadays, the tramway and the shops are gone, and the cars still dominate the scene on the wide streets of its parameters. By that, it looks like a deserted space between the heavy vehicular flow.

Piazza del Duomo is surrounded by homogeneous structures of monumental buildings, such as the Duomo and the Royal Palace, alongside many other prominent buildings such as Galleria Vittorio Emanuele II, Palazzo Carminati and Palazzo Arengario that are also considered touristic attractions (Klaos, 2018). Together, they formed a semi enclosed space that follows the human scale and gives a sense of belonging once inside. What enhances such a feeling, is that the space is surrounded by large arches that create a transition space and act as entrances (Niko, 2016). 


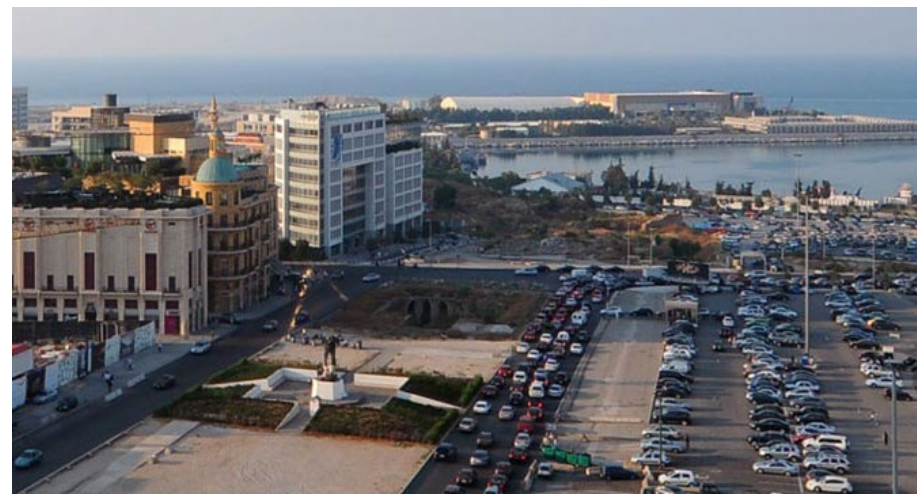

Figure 5. Martyrs' Square, Beirut (by Solidere)

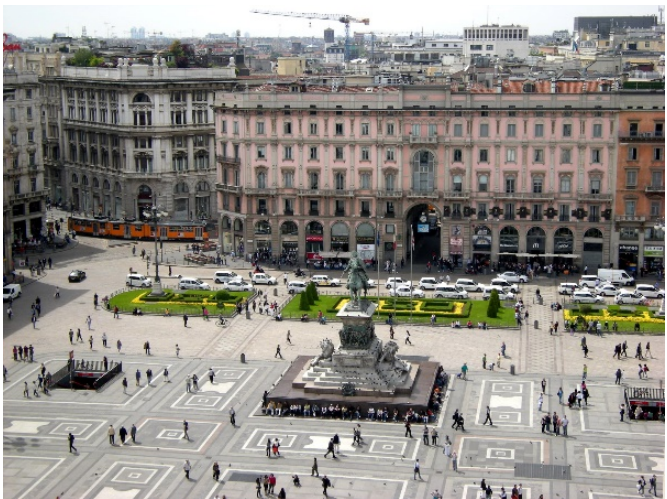

Figure 6. Piazza Del Duomo, Milan (Leandro Neumann Ciuffo)

This reflects a main issue when looking at Martyrs' Square in Beirut, where the square's surroundings were reconstructed in a haphazard manner and with buildings of different scales, styles, and periods. This was either due to the war that kept interrupting development projects, or to the privatisation of lands which did not follow any general planning or policies (Verdeil et al., 2008). This had a huge influence on the feel of the space, it erased the sense of human scale within the space. Also, the heterogeneity of the surrounding facades, in addition to the undefined functions of the buildings, deemed the space to have an undefined physical boundary. Having such a characteristic in a public space erases the sense of belonging and the feel of safety within the space, contrasting with the characteristics of Piazza del Duomo mentioned earlier. At the end of this point, we must take into consideration the relatively newly built "Al Amin Mosque", which opened in 2005. The mosque is considered a monumental and significant landmark adjacent to the square. However, such landmark did not help in reviving the square, like the Milan Cathedral did, due to several reasons. Some of these reasons are the lack of any historical significance and that it is still being used as a mosque strictly for the Muslim population in the area; unlike the Milan Cathedral which is now a museum for all.

\section{The culture}

Eventually, it is worth mentioning that another major influence on the usage of these spaces, are the cultural and environmental factors). The idea of using public squares is essential/pivotal within the daily life of Europeans, due to traditional, religious, and environmental factors. Environmentally, the importance of a public open space in Europe is embraced by the rarity of sunny days, especially in Northern European countries. This allows these spaces to be an opportunity to enjoy those sunny days. This marks another important difference with Middle Eastern countries. On the religious level, privacy, specifically women's privacy, is sacred in Arab countries due to the influence of the Islamic religion. Therefore, shopping centres and malls usually tend to be more common as they enhance privacy with their enclosed structure (Al-Bishawi et al., 2017). In addition to them being considered more safe and secure; something that public squares failed to provide in Arab cities after the lack of consideration of the local environmental, traditional and religious factors in planning. 


\section{Factors of success}

The Greek's agora was created as a representation of democracy, a space for the people, by the people (Arch2o, 2020). A public space is where ideas are shared, memories are conserved and identities are created; it is communal for everyone regardless of class or colour. Architects, planners, and governments are nothing but messengers that provide it for the citizens, who in turn, create this identity within the space (Arch2o, 2020). Due to the huge political and economic influence, the public spaces that were imported into the Arab world did not specifically embrace the needs of the people, as seen in the example of Martyr's Square. Until 20I I, and with the Arab uprising against their governments, the chains shackled around these spaces were finally broken, and the people, rich and poor, took a process to reclaim them as their own (Rabbat, 2012). Taking a look at the Lebanese revolution in 17 October 2019, the upper-class spaces built by Solidere in Beirut's city centre regained their civic quality; holding intellectual debates and allowing small business and street vendors to use these spaces for the first time. This scene was spread all over Lebanon, reclaiming privatised public spaces, and even neglected inaccessible places. These public spaces in Lebanon shared one thing, a modernist intention inspired by the western movement (Arch2o, 2020), and influenced by political and economic factors rather than social and cultural. However, their weaknesses were backed up by different reasons, which the revolution was partially able to rectify. Once the people were given the opportunity to reclaim these spaces, they were able to domesticate them in a way that fits their actual needs, and reflect their own identity and culture. One reason can be explained through the example of "The Egg", an egg-shaped building in the city centre that was built with a brutalist vision. It was elevated, and by that, disconnected with its form and style from its surroundings. "The Egg", as shown in Figures $7 \& 8$, was built before the war as a theatre; however, it was unfinished due to the outbreak of the 1975 war that left it abandoned and deemed it forbidden from use since then (Sinno, 2020).

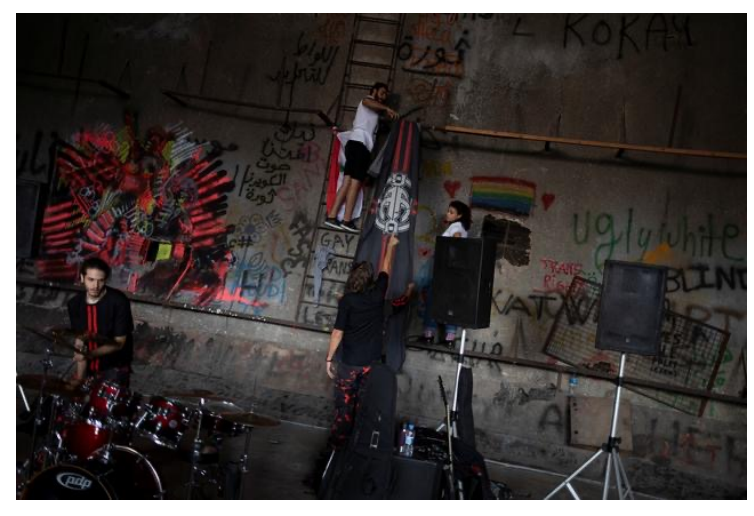

Figure 7. “The Egg” interior, Beirut 2020 (Reuters/Alkis Konstantinidis)

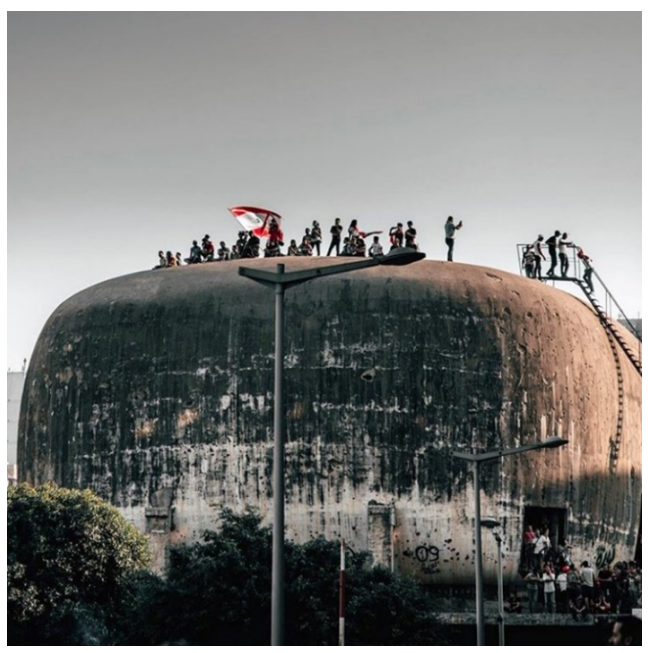

Figure 8. “The Egg”, Beirut 2020 (by Louay Kabalan)

By the hands of the revolutionaries, "The Egg" was transformed into a centre of expression and acceptance, reflected through art, music and intellectual talks which 
included the poor, the rich, men, women, and the LGBTQ community for the first time in decades. Moreover, we can take Samir Kassir Garden as an example, which was highly influenced by western standards in its architectural minimalism. Nonetheless, it remains empty through most, if not all, of the day. The design of this space took care of the small details, it carefully studied visual balance between its three therapeutic elements of the tree, water, and marble to provide a quiet place within a heavy context (AKDN, 2020). By experiencing the space, the reality is different. The space was designed as one elongated bench, overlooking a crowded vehicular street and a hotel/café that is considered for the upper-class. Therefore, the heavy vehicular flow on that facing street refutes its function as a calm and therapeutic space. On another hand, the space lacks any functions for the middle-to-lower class people around it, and the elongated seating layout does not enhance the opportunity for any social interaction. With the revolution, the setting of the space was transformed to an inclusive space for everyone from all classes and races, where people can meet, express their identity, share their thoughts, learn, and grow as a community. It now includes a variety of talks, lectures, and debates. The people were able to restructure the space from an elongated horizontal setting into a circular space, where they can sit and interact, neglecting the initial design, as seen in Figure 10 (Aseel Naamani/International Alert).

Eventually, in the case of Martyrs' Square in Beirut, the people redesigned the space. Vehicular streets were blocked, making it a pedestrian friendly open space, a safe space for all users, and a symbol of the revolution. These steps were enough to transform Martyrs' Square into a hub for expression and art. The landmark of the Martyrs' Statue was revived, in addition to other art pieces built by the people, which enhanced this symbolism. It was full of street vendors and tents for talks and debates, which dealt with political, economic, and social awareness. Moreover, and for the first time, it became a space for common celebrations, marriages and it hosted the 2020's New Year's Eve, where the people worked together to celebrate. It was free and open for everyone.

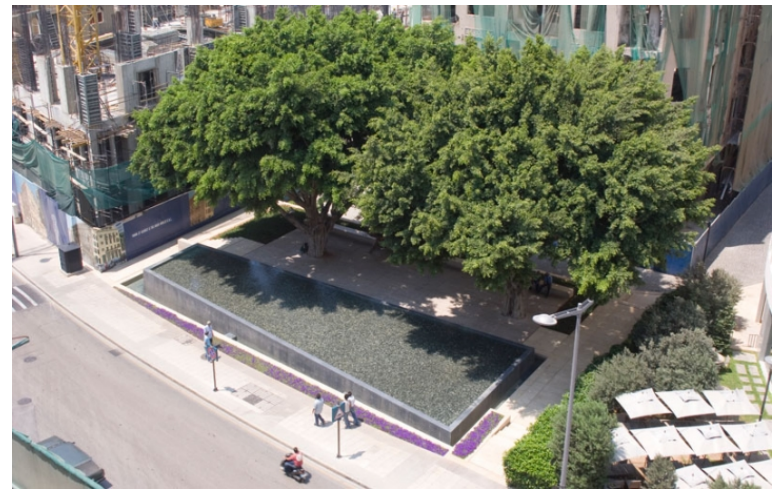

Figure 9. Samir Kassir Garden (by Roger Moukarzel)

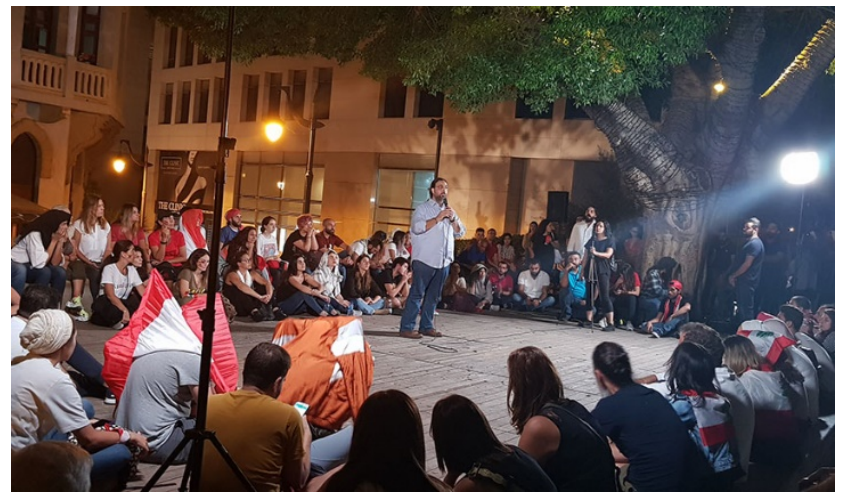

Figure 10. Samir Kassir Garden, Beirut 2020 (Aseel Naamani/International Alert)

\section{Conclusion}

Looking at the findings, and mixing it with the literature review, we can deduct a variety of issues that followed the implementation public spaces in the Arab world, and especially in Lebanon. These spaces that were influenced by the European idea of public space lacked various considerations that create the essence of the public space. 
Following the aim of this research into answering the question of whether the circumstances of implementation of the European public spaces in the Arab world were sufficient for their success, and to conclude what other factors that are essential to ensure the success of these public spaces were lacking. The three objectives set worked together to divide the research question into three parts and satisfy each with the example of Beirut, Lebanon. In the literature review, we were able to deduct that the circumstances of implementations were highly influenced by political and economic factors. This was concluded from the following. First, the wars and political sectarianism that dominated the scene of Beirut and Lebanon in general; second, privatisation that led to the aim of profitability with the absence of any governance, leading to upper-class spaces which are not accessible for the lower class; and the lack of any policies or general planning leading to a haphazard reconstructions process. These were backed up in the comparative analysis done between Martyr's Square and Piazza del Duomo. Also, it was seen that other issues resulted from the previous mentioned factors, such as vehicular dominance, heterogeneity of the space's surroundings with no significant use of function, and the lack of the feel of safety and belonging that was caused by all these elements.
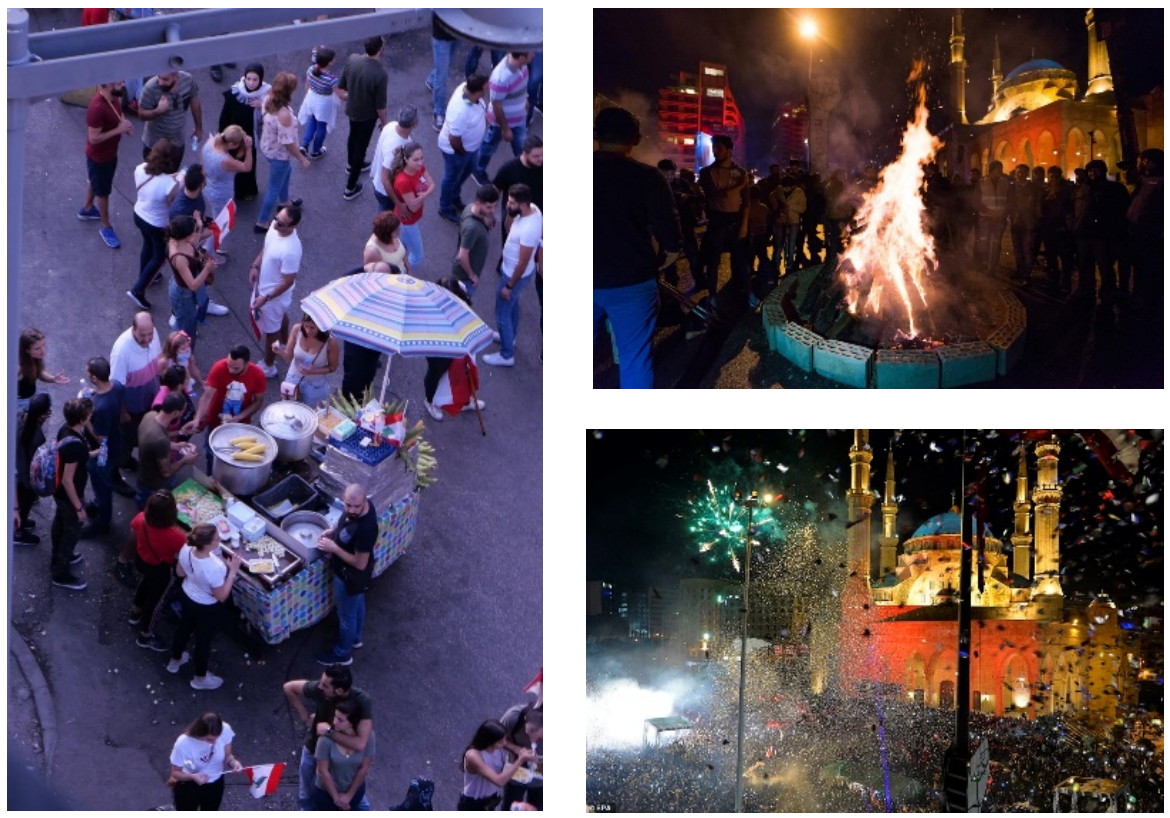

Figure I I. Martyr's Square During the Lebanese Revolution 2019-2020 (by Wael Hamzeh)

Eventually, and with the final objective, we were able to prove that once the people are given an opportunity to transform these spaces, the latter takes a leap of success. What was previously missing was the consideration of the human scale and of the society. The political and economic influence of the erection of these spaces lacked the design sensitivity towards creating a space for the people to use, meet and socialise. By that they overpowered the social and cultural factors that should have dominated the intention of these spaces. Similar to the design of public spaces in Europe, where it is believed that public space is where people from all backgrounds gather and interact in a form of selfexpression that enables the acceptance of their differences and leads to the formation of a collective identity and vision towards the future (Arch20, 2020). 
What Happened to the Public Spaces of the Arab World?

\section{References}

Arch2O.com (2017). What Happened to Public Space? A Quick Guide Through Europe's History. [online] Available at: https://www.arch2o.com/happened-public-space-quick-guideeuropes-historyl

Asfar (20I2). BEIRUT'S MAKE OVER. The meaning of "Solidere" I5 years later. [online] Available at: https://www.asfar.org.uk/beiruts-make-over-the-meaning-of-solidere-I5-yearslater/.

Al-Bishawi, M., Ghadban, S. and Jørgensen, K. (20I7). Women's behaviour in public spaces and the influence of privacy as a cultural value: The case of Nablus, Palestine. Urban Studies Journal, [online] Vol. 54(7), pp.I559-1577. Available at: http://journals.sagepub.com/home/usi [Accessed 21 Jun. 2019].

AKDN (n.d.). Samir Kassir Square | Aga Khan Development Network. [online] Available at: https://www.akdn.org/architecture/project/samir-kassir-square [Accessed 20 Jun. 2020].

Comero, D., Lo Verso, L., \& Marino, P. (2016). Metropoli Milano, 3(322). Milan: Wayback Machine.

Faleh, M. (n.d.). How city squares can be public places of protest or centres of state control. [online] The Conversation. Available at: https://theconversation.com/how-city-squares-canbe-public-places-of-protest-or-centres-of-state-control-102275 [Accessed 24 Jun. 2020].

Fawaz, M. (20/4). Planning Beirut During the French Mandate: The Construction of a Modern City and Its Legacy. [online] Jadaliyya. Available at: https://www.jadaliyya.com/Details/32202 [Accessed 27 June 2020].

Knoope, P. (2018). The Arab Spring and The Securitisation Of Space. [online] DOC Research Institute. Available at: https://doc-research.org/2018/01/arab-spring-securitisation-space/ [Accessed 24 June 2020].

Klaos, Y. (2018). Duomo Square, Milan: Cathedral of Milan, Royal Palace, Victor Emanuel II Gallery. [online] Available at: https://life-globe.com/en/duomo-square-milan/ [Accessed 20 Jul. 2020].

Lennard, S. (2004). Genius of The European Square | International Making Cities Livable. [online] Livablecities.org. Available at: https://www.livablecities.org/articles/genius-europeansquare [Accessed 20 June 2020].

Metrics, D. (2020). Capital Facts for Beirut, Lebanon [online] https://www.worldscapitalcities.com/capital-facts-for-beirut-lebanon/ [Accessed 12 July 2020].

Niko N. (2016). Piazza del Duomo. https://nomadicniko.com/2016/|2/2I/piazza-del-duomo/

Rabbat N. (2012). The Arab Revolution Takes Back the Public Space. Critical Inquiry. 39. 198208. DOI: 10.1086/668055.

Sanburn, J. (201 I). Square Roots: How Public Spaces Helped Mold the Arab Spring. [online] TIME.com. Available at: http://content.time.com/time/world/article/0,8599,207/404,00.html [Accessed 30 June 2020].

Sinno, W. (2020) "How People Reclaimed Public Spaces in Beirut during the 2019 Lebanese Uprising", The Journal of Public Space, 5(I), Pp. 193-218. doi: https://doi.org//0.3289|/jps.v5il.1258

The Economist. (2016). No bed of roses. [online] Available at: https://www.economist.com/middle-east-and-africa/2016/06/09/no-bed-of-roses [Accessed I5 July 202I].

Verdeil E. \& Nasr J. (2008). The reconstructions of Beirut, in Salma K. Jayyusi, Renata Holod, Attilio Petruccioli and André Raymond. The City in the Islamic World, Brill, Pp. I II6-II4I, Handbook of Oriental Studies.

World Cities Culture Forum (2019). Percentage of public green space (parks and gardens). [online] Available at: http://www.worldcitiescultureforum.com/data/of-public-green-spaceparks-and-gardens 